\title{
Center for Electronics and Electrical Engineering
}
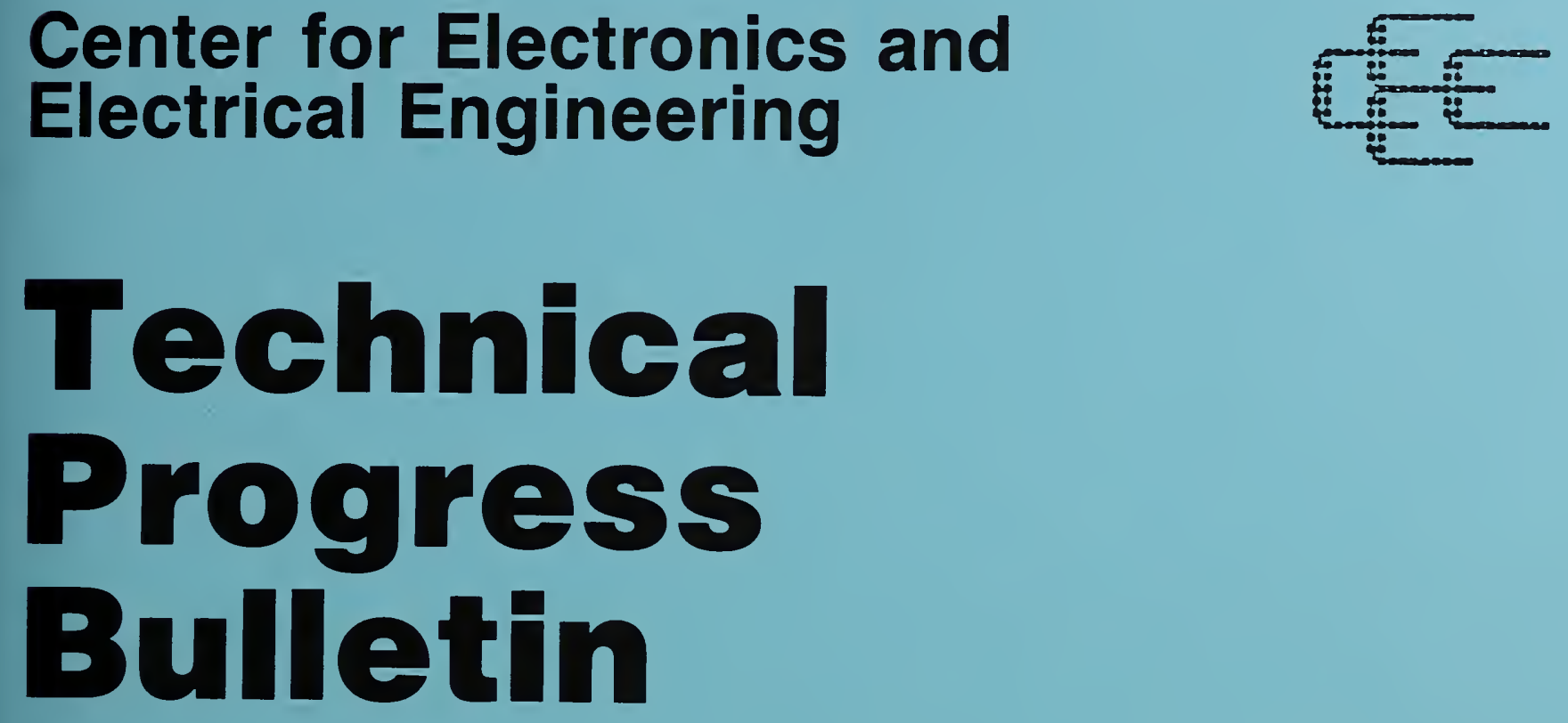

Covering Center Programs, January to March 1987, with 1987 CEEE Events Calendar

July 1987

U.S. Department of Commerce National Bureau of Standards National Engineering Laboratory Gaithersburg, Maryland 20899

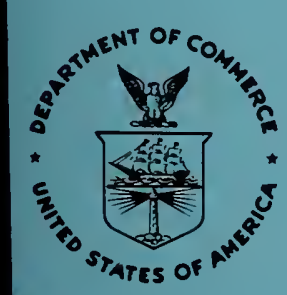


This is the eighteenth issue of a quarterly publication providing information on the technical work of the National Bureau of Standards Center for Electronics and Electrical Engineering. This issue of the CEEE Technical Progress Bulletin covers the first quarter of calendar year 1987.

Organization of Bulletin: This issue contains abstracts for all Center papers released for publication by NBS in the quarter and citations and abstracts for center papers published in the quarter. Entries are arranged by technical topic as identified in the table of contents and alphabetically by first author under each subheading within each topic. Unpublished papers appear under the subheading "Released for publication". Papers published in the quarter appear under the subheading "Recently Published". Following each abstract is the name and telephone number of the individual to contact for more information on the topic (usually the first author). This issue also includes a calendar of center conferences and workshops planned for calendar year 1987, some preliminary announcements for calendar year 1988, and a list of sponsors of the work.

Center for Electronics and Electrical Engineering: Center programs provide national reference standards, measurement methods, supporting theory and data, and traceability to national standards.

The metrological products of these programs aid economic growth by promoting equity and efficiency in the marketplace, by removing metrological barriers to improved productivity and innovation, by increasing $U$. S. competitiveness in international markets through facilitation of compliance with international agreements, and by providing technical bases for the development of voluntary standards for domestic and international trade. These metrological products also aid in the development of rational regulatory policy and promote efficient functioning of technical programs of the Government.

The work of the Center is divided into two major programs: the Semiconductor Technology Program, carried out by the Semiconductor Electronics Division in Gaithersburg, MD, and the Signals and Systems Metrology Program, carried out by the Electrosystems Division in Gaithersburg and the Electromagnetic Fields and Electromagnetic Technology Divisions in Boulder, CO. Key contacts in the Center are given on the back cover; readers are encouraged to contact any of these individuals for further information. To request a subscription or for more information on the Bulletin, write to CEEE Technical Progress Bulletin, National Bureau of Standards, $\overline{\text { Metrology }}$ Building, Room B-358, Gaithersburg, MD 20899 or call (301) 975-2220.

Center sponsors: The Center Programs are sponsored by the National Bureau of Standards and a number of other organizations, in both the Federal and private sectors; these are identified on page 22.

Note on Publication Lists: Guides to earlier as well as recent work are the publication lists covering the work of each division. These lists are revised and reissued on an approximately annual basis and are available from the originating division. The current set is identified in the Additional Information section, page 19. 
INTRODUCTION

SEMICONDUCTOR TECHNOLOGY PROGRAM

Silicon Materials • • • • • • • • • • • • • • • • • •

Gallium Arsenide Materials • • • • • • • • • • • • • • • • .2

Dimensional Metrology • • • • • • • • • • • • • • • • •

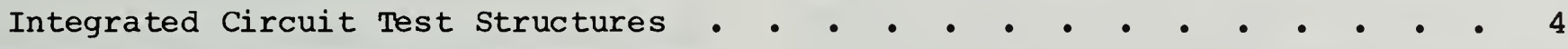

Device Physics and Modeling . • • • • • • • • • • • • •

FAST SIGNAL ACQUISITION, PROCESSING, \& TRANSMISSION • • • • • • • •

Waveform Metrology • • • • • • • • • • • • • • • • •

Cryoelectronic Metrology • • • • • • • • • • • • • • • . . 8

Antenna Metrology • • • • • • • • • • • • • • • • • • 9

Noise Metrology • • • • • • • • • • • • • • • • • •.$~ \bullet 10$

Microwave and Millimeter-Wave Metrology . • • • . . . . . . . 10

Optical Fiber Metrology • • • • • • • • • • • • • • • •

Electro-Optic Metrology • • • • • • • • • • • • • • • •.$~ 11$

Other Fast Signal Topics • • • • • • • • • • • • • • • • 12

ELECTRICAL SYSTEMS • • • • • • • • • • • • • • • • • •

Power Systems Metrology • • • • • • • • • • • • • • • • • 13

Superconductors • • • • • • • • • • • • • • • • • • •

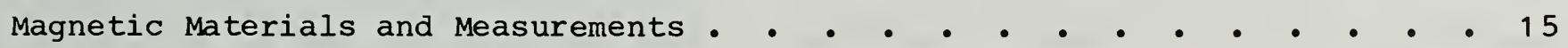

ELECTROMAGNETIC INTERFERENCE • • • • • • • • • • • • • • •

Radiated Electromagnetic Interference • • • • • • • • • • • • 15

ADDITIONAL INFORMATION • • • • • • • • • • • • • • • • • •

1987 CEEE CALENDAR • • • • • • • • • • • • • • • • • • • • • 19

SPONSOR LIST • • • • • • • • • • • • • • • • • • • • • •

KEY CONTACTS IN CENTER, CENTER ORGANIZATION • • • • • • • • • • . back cover 


\section{SEMICONDUCTOR TECHNOLOGY}

Silicon Materials

Recently Published

Ehrstein, J. R., Spreading Resistance Measurements - An Overview, Emerging Semiconductor Technology, ASTM STP 960, D.C. Gupta and P.H. Langer, eds., pp. 453-479 (American Society for Testing and Materials, 1987).

Spreading resistance is the most versatile electrical technique for characterizing depth profiles in silicon. However, it is being increasingly challenged as an analytical method by shrinking device geometries. Consequently, refinement of such aspects as probe conditioning, sample preparation and bevel angle measurement is needed, and traditional practice regarding calibration, algorithms and profile interpretation must be reexamined. Based on examples drawn from the author's work, multilaboratory experiments, and recent literature to illustrate and discuss these topics, this paper will attempt to summarize the current status of the measurement and its interpretation showing both strong points and apparent limi tations.

[Contact: James R. Ehrstein, (301)

975-2060]

Gladden, W. K. , and Baghdadi, A., Free Carrier Absorption and Interstitial Oxygen Measurements, Emerging Semiconductor Technology, ASTM STP 960, D.C. Gupta and P.H. Langer, eds., pp. 353-364 (American Society for Testing and Materials, 1987).

The infrared (IR) absorption of both nand p-type silicon samples were measured over the concentration range $\sim 10^{15} \mathrm{~cm}^{3}$ to $10^{17} \mathrm{~cm}^{3}$. The free carrier absorption exhibited a power-law dependence with wavenumber. The data were fit to a logarithmlc function with this dependence, and these results were applied to the determination of the baseline from which to compute the corrected net IR absorption at $1107 \mathrm{~cm}^{-1}$ due to interstitial oxygen. Application of this correction for the free carrier absorption results in an improvement of $3 \%-30 \%$ in the accuracy of the oxygen content determination at concentrations above $10^{16}$ atoms $/ \mathrm{cm}^{3}$.

[Contact: Aslan Baghdadi, (301)

975-2062]

Gallium Arsenide Materials

Recently Published

Bouldin, C.E., Forman, R.A., and Bell, M.I., Conversion Yield EXAF'S Measurements of Ion-Damaged GaAs, Physics Review B, Vol. 35, No. 3. pp. 1429-1432 (15 January 1987).

Extended $x-r a y$ absorption fine structure (EXAFS) measurements of ion-implanted GaAs have been made using conversion electron detection. This total electron yield detection technique (termed CEEXAFS) allows near-surface sensitivity with a sampling depth of 700 to $1000 \AA$. Measurements of the $\mathrm{Ga}$ absorption edge show that implantation of $10^{16} \mathrm{~cm}^{-2}$ of $\mathrm{Zn}$ ions at $180 \mathrm{KeV}$ into GaAs produces heavy lattice damage (amorphization) to a depth of about 700 to $900 \AA$. After rapid thermal annealing, the amorphous layer is found to be recrystallized and structurally indistinguishable from unimplanted material. The sampling depth of CEEXAFS has been measured for the first time, using standards with known depth dependent structure. The CEEXAFS technique greatly reduces $\mathrm{Bragg}$ peak contamination of the EXAFS signal from single crystal materials, and allows measurement of a variety of samples which cannot be fabricated as thin layers for conventional transmission or fluorescence EXAFS measurements. The method permits examination of the local environment of host atoms (in this case Ga) in the near surface region without interference from the underlying bulk and without the distortions found in fluorescence EXAFS measurements of concentrated samples.

[Contact: Charles E. Bouldin, (301)

975-2046] 
Dimensional Metrology

\section{Recently Published}

Larrabee, R.D., Submicrometer Optical and SEM Linewidth Metrology, Proceedings of the 1987 measurement Science Conference, Irvine, California, January 29-30, 1987, pp. V-D (1)-V-D (10).

The feature sizes on modern integrated circuits are presently taxing the ability of visible-light optical systems to perform the necessary dimensional measurements required during their production. With the shrinking of feature dimensions to the micrometer and submicrometer level, diffraction and finite wavelength become the limitations of existing optical systems. In an effort to overcome these limitations, metrology systems based on the scanning electron microscope (SEM) have appeared and are often assumed to be the panacea of all the problems and the limitations of existing optical systems. In response to the application of the SEM to these problems, new optical systems have appeared including ultraviolet and laser scanning systems. This paper takes a critical look at the basic optical and SEM metrologies, outlines the program at the National Bureau of Standards to provide micrometer and submicrometer feature-size standards for both technologies, and discusses what can be done in practice until suitable standards become available.

[Contact: Robert D. Larrabee, (301)

975-2298]

Larrabee, R.D., Submicrometer Optical Linewidth Metrology, to be published in the Proceedings of SPIE - The International society for optical Engineering, P.O. Box 20, Bellingham, WA 98227 [conference Santa Clara, California, March 1-6, 1987].

The National Bureau of Standards (NBS) has had a continuing program to develop optical linewidth standards for the integrated circuit industry for over 10 years. The past work has concentrated on the development and the certification of photomask linewidth and pitch standards. The recent work is directed at extending the feature sizes on these standards to cover the range from 0.5 to $30 \mu \mathrm{m}$, and at doubling the certification accuracy to $0.025 \mu \mathrm{m}$. Features with heights larger than approximately $1 / 4$ the wavelength of the illuminating light cannot be modeled as zero-thickness layers as is done for photomasks. The development of models to handle this thick-layer case and to develop practical edge-detection criteria are currently under development at NBS. However, at the present time, it is generally not possible to interpret the image profiles of thick features and thereby measure an accurate linewidth. The basic obstacles that must be overcome to achieve accurate submicron feature size measurements for these features are reviewed, and the prospects for future NBS optical standards for features such as photoresist lines on silicon wafers are assessed. Some suggestions about what to do until these standards become available are given.

[Contact: Robert D. Larrabee, (301)

975-2298]

Nyyssonen, D., A Practical Method for Edge Detection and Focusing for Linewidth Measurements on wafers, Optical Engineering, Vol. 26, No. 1, pp. 081-085 (January 1987).

Lack of precision and accuracy of inprocess critical dimension (CD) measurements of linewidth continues to be a serious problem at micrometer and submicrometer dimensions. Even with highly repeatable optical linewidth measurement systems, variable "offsets" or errors have been shown to occur with changes in process variables such as thickness of the patterned layer and sublayers and changes in the indices of refraction of the materials. All of these variations result in a change in the optical phase difference that occurs on reflection at the line edge and, therefore, result in changes in the structure of the optical image. Although an accurate coherent 
Dimensional Metrology (cont'd.)

optical edge-detection method has been developed, it requires accurate knowledge of this phase difference, which is not always possible in $C D$ measurements. This paper proposes a new dual-threshold method for edge detection and focusing, based on image theory, which can be adapted to most optical microscope based measurement systems. It does not require knowledge of the phase discontinuity at the line edge. The accuracy of this criterion is compared to two more widely used criteria, (1) the minimum and (2) 50\% threshold, and it is concluded that, when the phase difference is unknown and varies with normal processing, the new dual-threshold method is the superior method.

[Contact: Rohert L. Larrabee, (301)

975-2298]

Postek, M.T., Submicrometer Dimensional Metrology in the Scanning Electron Microscope, to be published in the Proceedings of SPIE - The International Society for Optical Engineering, P.O. Box 20, Bellingham, WA 98227 [conference Santa Clara, California, March $1-6,1987]$.

The National Bureau of Standards has initiated a program to develop scanning electron microscope linewidth measurement standards for the integrated circuit community. This program involves the development of: a scanning electron microscope-based linewidth measurement and standard reference material certification instrument, the necessary electron beam/sample interaction modeling, and the appropriate micrometer and submicrometer artifacts. The basic problems that must be overcome to achieve accurate submicrometer feature size measurements in the scanning electron microscope for these artifacts are reviewed and some suggestions of what can be done to "bridge-the-gap" until such standards become available are given.

[Contact: Michael T. Postek, (301)

975-2299]
Integrated Circuit Test Structures

Released for Publication

Cresswell, M.W., Pessell, N., Betsch, R.J., Linholm, L.W., and Radack, D.J., Sub-Micron Lithography Characterization Using an Expert System, to be published in the Proceedings of SPIE - The International Society for Optical Engineering, P.O. Box 20, Bellingham, WA 98227 [conference Santa Clara, California, March 1-6, 1987].

This paper describes a test chip, test results, rule generation techniques, and an expert system for characterizing the performance of a sub-micron lithography process. Examples of test results, data reduction techniques, and expert system output are given. The objective of this work is to develop a system for automatic process diagnosis.

[Contact: Loren W. Linholm, (301)

975-2052]

Device Physics and Modeling

Released for Publication

Kim, J.S., The Effect of the Gate oxide Thickness on the Speed of MCS Integrated Circuits.

A simple analysis is presented for the effect of the gate oxide thickness on the circuit speed in a short-channel CMOS/inverter delay circuit. The present analysis is performed within the first-order theory of the MOS transistor. The result of the analysis shows that an optimum value of the gate oxide thickness exists, beyond which a further scaling of the gate oxide will not improve but degrade the circuit speed. The circuit speed corresponding to this optimum oxide thickness is the ultimate upper limit theoretically possible in a given MOS integrated circuit. The optimum value of the gate oxide thickness, to a first-order approximation, is proportional to the channel width $W$, but it is independent of the channel length L. In particular, 
Device Physics \& Modeling (cont'd.)

for wide channel devices, this optimum value exceeds the $5-\mathrm{nm}$ to $30-\mathrm{nm}$ range, which is of practical significance in the design and processing of advanced VLSI circuits. At the optimum oxide thickness, the square-root of the net propagation delay is the sum of two components: the square-root of a purely parasitic component and the square-root of a device-dependent component.

[Contact: Jin S. Kim, (301) 975-2238]

Recently Published

Albers, J., Monte Carlo Calculation of Primary Kinematic knock-On in SIMS, Emerging Semiconductor Technology, ASTM STP 960, D.C. Gupta and P.H. Langer, eds., pp. 535-557 (American Society for Testing and Materials, 1987).

Secondary Ion Mass Spectrometry (SIMS) occupies a central position in atomic profiling of semiconductor device structures. One of the possibilities for distortion of the profiles is the phenomenon of knock-on, in which the incident sputtering ion transfers enough kinetic energy to the impurity atoms to push them deeper into the material before they can be sputtered and counted. The effects of sputtering and primary kinematic knock-on are investigated by means of a Monte Carlo code previously used to study ion implantation processes. In particular, the dependence of the primary kinematic knock-on on the mass and energy of the sputtering ion as well as the mass of the impurity atom are presented.

[Contact: John Albers, (301) 975-2075]

\section{Albers, J., Some Aspects of Spreading} Resistance Profile Analysis, Emerging Semiconductor Technology, ASTM STP 960, D.C. Gupta and P.H. Langer, eds., pp. 480-501 (American Society for Testing and Materials, 1987).

The calculation of resistivity profiles (and carrier density profiles) from spreading resistance requires the use of a correction factor. The present status of the calculation of the correction factor based upon the Schumann and Gardner multilayer solution of Laplace's equation is reviewed and discussed. Recent calculations of carrier densities from atomic densities are also discussed. In particular, the numerical solutions of the semiconductor equations are reviewed, and their implications in the interpretation of spreading resistance measurements for profiling shallow layers are presented. The limitations of the multilayer Laplace equation analysis of spreading resistance in VLSI profiling are also discussed.

[Contact: John Albers, (301) 975-2075]

Marchiando, J.F., and Albers, J., Effects of Ion-Implantation Damage on Two-Dimensional Boron Diffusion in Silicon, Journal of Applied Physics, Vol. 61, No. 4, pp. 1380-1391 (15 February 1987).

Well-defined control of boron implanted in silicon during a high-temperature short-time anneal is important in calculation of shallow $\mathrm{p}-\mathrm{n}$ junction profiles in metal oxide-semiconductor field-effect transistors (MOSFETs). During an anneal, boron may exhibit enhanced diffusion lasting about a second. Here, displacement damage is removed largely by release and condensation of single vacancies, which enhance the boron diffusion via the charged vacancy mechanism. Model 2-D distributions of boron and displacement damage implanted near a mask edge are used to calculate the redistribution of boron resulting from a seven-second anneal. Boron redistributes further into the bulk, while leaving the channel length unaffected. The redistribution agrees favorably with that reported in the literature.

[Contact: Jay F. Marchiando, (301)

975-2088]

FAST SIGNAL ACQUISITION, PROCESSING, AND TRANSMISSION

Waveform Metrology 
Waveform Metrology (cont'd.)

Released for Publication

Oldham, N.M., Parker, M.E., Young, A., and Smith, A.G., A High Accuracy, 10 $\mathrm{Hz}$ - $1 \mathrm{MHz}$ Automatic AC Voltage Calibration System, to be published in the proceedings of the IMTC/87 Conference Record (IEEE Instrumentation/Measurement Technology Conference), Boston, Massachusetts, April 27-29, 1987.

An automatic system for calibrating high accuracy ac voltmeters and calibrators is described. The system is based on traditional coaxial thermal voltage converters to provide measurement uncertainties of 5 to $20 \mathrm{ppm}$ in the audio frequency range and 5 to $150 \mathrm{ppm}$ over the tull range from $10 \mathrm{~Hz}$ to $1 \mathrm{MHz}$. Specialized hardware and measurement techniques make it possible to achieve these uncertainties in test periods of approximately one minute. Random errors introduced by the system are typically less than $2 \mathrm{ppm}$ (one standard deviation).

[Contact: N. Michael Oldham, (301)

975-2408]

Souders, T.M., Schoenwetter, H.K., and Hetrick, P.S., Characterization of a Sampling Voltage Tracker for Measuring Fast, Repetitive Signals, to be published in the Proceedings of the IMTC/87 Conference Record (IEEE Instrumentation/Measurement Technology Conference), Boston, Massachusetts, April 27-29, 1987.

An equivalent time-sampling and digitizing system is described, together with test methods for characterizing its dynamic performance. Time-base errors, linearity errors, step-response parameters, and frequency response are considered, and typical measurement results are included. The system is capable of state-of-the-art measurements at rf trequencies.

[Contact: T. Michael Souders, (301)

975-2406]
Stenbakken, G.N., Laug, O.B., Perrey, A.G., Bell, B.A., and Kibalo, T.H., NBS wideband Sampling wattmeter, to be published as NBS Technical Note 1221.

The design and operation of a wideband sampling wattmeter capable of measuring distorted power signals with fundamental frequencies from $1 \mathrm{~Hz}$ to $10 \mathrm{kHz}$ and harmonics up to $100 \mathrm{kHz}$ are described. The microprocessor-controlled wattmeter uses asynchronous sampling of the voltage and current signals. The errors associated with this type of operation are described as are various methods of correcting some of these errors. A hardware multiplier-accumulator is used to allow a large number of power samples to be integrated for each measurement. Sampling rates are variable up to a maximum of $300 \mathrm{kHz}$. A direct-memory-access unit is used to capture 4096 samples of both the voltage and current signals. These data are used to calculate the average and rms of these signals. A special feature of the sampling wattmeter is the use of programmable time-delay circuits to compensate for differential time delays between the two input channels. Performance checks of the wattmeter show that it has a measurement uncertainty of less than \pm 0.1 percent of full-scale range over the indicated frequency range.

This technical note gives schematics of the circuits and describes their operation. The software is described, and flow charts and selected program listings are provided for the PASCAL programs. The results of calibration of the instrument over the past year are also presented.

[Contact: Gerald N. Stenbakken, (301) 975-2440]

Recently Published

Adair, R.T., Ehret, R.L., and Livingston, E.M., Measurement of RF signal Generator Phase Noise Using a OneGenerator Delay-Iine Method, IEEE Transactions on Instrumentation and 
Waveform Metrology (cont'd.)

Measurement, Vol. IM-35, No. 4, pp. 496-502 (December.1986).

A technique is described which utilizes a single generator and a delay line for the measurement of frequency-domain phase noise in synthesized signal generators. Terms are defined and equations developed for theory and calculations of normalized phase-noise sideband power in a $1-\mathrm{Hz}$ bandwidth offset $20 \mathrm{kHz}$ from signal frequencies of interest. The system described covers the range from 0.45 to $2000 \mathrm{MHz}$. The function and contribution of each component in the measurement system is presented. Advantages of this method are discussed and a brief error analysis is given.

[Contact: Robert T. Adair, (303)

497-3461]

Kuffel, J., Malewski, R.A., van Heeswijk, R., and Lawton, R.A., Dynamic Performance of Digital Recorders Used for Monitoring High-Voltage Impulse Tests, IEEE Transactions on Instrumentation and Measurement, Vol. IM-35, No. 4, pp. 591-595 (December 1986).

Frequency- and time-domain characteristics of digital transient recorders (in short, digitizers) are discussed in order to establish the requirements on digitizers used for high-voltage testing. Results of an experimental study performed on a $200-\mathrm{MHz}$ 8-bit digitizer are presented and related to the design features of this instrument. The inherent design characteristics and their influence on the digitizer dynamic performance are analyzed in view of simulation of the digitizer through a computer model.

[Contact: Robert A. Lawton, (303)

497-3339]

Nahman, N.S., Status and Future Directions of Picosecond Donain Waveform Measurements, Time-Domain Measurements in Electromagnetics, E.K. Miller, ed., Chapter 2 (Van Nostrand Reinhold Co., New York, NY, 1986), pp. 45-71.

The main purpose of this chapter is to (1) summarize the present-day capability in time-domain measurements for pulses or transient signals whose shape (evolution with time) occurs on a time scale of the order of picoseconds, and (2) offer some opinions as to the future directions of electrical and optical picosecond-domain pulse waveform measurements. Consequently, the techniques and other data presented here are limited to those suitable for such fast signals. For example, all of the methods cited recognize that the signal-circuit interconnections or transmission paths in devices and in instrumentation are distributed or wave-guiding in nature.

The review of the state of the art of picosecond time-domain waveform measurements presented here includes measurements in both the electrical (dc through $\mathrm{mm}$ waves, etc.) the optical regions (infrared through visible, etc.) of the electromagnetic spectrum. This review is the latest edition of a series of reviews on high-speed pulse measurements compiled by the author commencing in 1967; specifically, this review updates the 1983 review. The significance of the Institute of Electrical and Electronic Engineers (IEEE) Pulse Standards 181 and 194 and of the identical International Electrotechnical Commission (IEC) Standards 469-1 and 649-2 is discussed briefly. The classification of time-domain measurements from the 1978 review is summarized and augmented with basic instrumentation block diagrams. The present-day capabilities are presented via temporal resolution state-ofthe-art charts using the 1978 format. For the reader's convenience, the 1978 charts are reproduced here, along with charts that show only those changes that have occurred since 1978. The references cited in all of the chart entries are contained in the list of references.

[Contact: Ramon C. Baird (303)

497-3301] 
Waveform Metrology (cont'd.)

Oldham, N.M., Techniques and Instruments for Autonated Electrical Measurements, MAPAN, Journal of Metrology Society of India, Vol. 1, No. 1 , pp. 25-27 (1986).

A summary of previous developments in the field of automated electrical measurements is presented.

[Contact: N. Michael Oldham,

975-2408]

Schoenwe ter, H.K., Flach, D.R., Souders, T.M., and Bell, B.A., A Precision Programable step Generator for Use in Autonated Test Systems, NBS Technical Note 1230 (December 1986).

A precision voltage step generator has been designed for use in automated systems to test the dynamic response of waveform recorders and other instruments. The programmable pulse parameters include transition polarity, pulse length, and repetition rate. The initial and final levels of voltage steps are each programmable within the range of $\pm 1 \mathrm{~V}$ for a $50-\Omega$ termination and within $\pm 5 \mathrm{~V}$ for a high impedance load. Voltage steps within these ranges settle to within $\pm 0.02 \%$ of full scale range in less than 22 and $26 \mathrm{ns,} \mathrm{respectively,}$ for small load capacitance. The corresponding transition durations are approximately 6 and 7 ns.

[Contact: Howard $K$. Schoenwetter, (301) 975-2414]

\section{Cryoelectronic Metrology}

\section{Released for Publication}

Peterson, R.L., Sinusoidal Response of dc SQUIDs for if Power Measurements, to be published in the NBS Journal of Research.

Current, power, and attenuation measurements with radiofrequency superconducting QUantum Interface Devices (SQUIDs) are based on the fact that the voltage from the microwave readout circuit can be made nearly a sinusoidal function of the magnetic flux threading the SQUID. We point out here that an asymmetric dc SQUID with sufficiently low inductance can achieve a very sinusoidal output voltage with good modulation depth. The spectral purity of the sinusoid can be substantially better than that obtained with rf SQUID systems. The purity improves with increasing asymmetry of the junction critical currents, and decreasing values of the $\mathrm{LI}_{C}$ product, where, $\mathrm{L}$ is the SQUID inductance and $I_{C}$ is the smaller of the critical currents. Results of several calculations are presented. Substantial improvement in SQUID methods of $r f$ current, power, or attenuation measurement may thus be possible with use of such dc SQUIDs.

[Contact: Robert L. Peterson, (303) 497-3750 or -3227]

\section{Recently Published}

McDonald, D.G., High Accuracy in Physics, Science, p. 829 (August 22, 1986).

Philip Abelson, in an editorial in Science, reviews the National Research Council report "Physics Through the 1990s" and writes "Of all the quantities in physics, time is by far the most accurately measured." I argue that the Josephson effect has comparable accuracy.

[Contact: Donald G. McDonald, (303) 497-5113]

Muhlfelder, B., Beall, J.A., Cromar, M.W., and Ono, R.H., Very Low Noise, Tightly Coupled, dc squID Amplifiers, Applied Physics Letters, Vol. 49, No. 17, October 27, 1986, pp. 1118-1120.

We have fabricated and tested thin-film, niobium edge junction, double transformer, dc superconducting quantum interference devices (SQUIDs) that were stable under room-temperature storage and thermal cycling and that had very good noise performance. The input inductance, 
Cryoelectronic Metrology (cont'd.)

approximately $1.7 \mu \mathrm{H}$, was large enough to facilitate good matching to many experiments. When the SQUID was operated as a small-signal amplifier, the minimum detectable energy per unit bandwidth $\left(\mathrm{S}_{\mathrm{e}}\right)$ was $5 \times 10^{-33} \mathrm{~J} / \mathrm{Hz}$ at $100 \mathrm{kHz}$, referred to the SQUID loop (uncoupled). The minimum detectable energy per unit bandwidth was $1.8 \times$ $10-31 \mathrm{~J} / \mathrm{Hz}$ at $100 \mathrm{kHz}$, referred to the input coil. The SQUIDs had good characteristics for flux-locked operation since the small signal $\mathrm{S}_{e}$ was low over a substantial range of bias current and magnetic flux. For operations in a flux-locked feedback circuit, $S_{e}$ was 6 $\times 10^{-32} \mathrm{~J} / \mathrm{Hz}$ at $1 \mathrm{kHz}$.

[Contact: James T. Beall, (303)

497-5989]

Antenna Metrology

Recently Published

Baird, R.C., Daywitt, W.C., Newell, A.C., Perera, S., Repjar, A.G., Wait, D.F., and Estin, A.J., Calibration Requirements for EHF Satellite Communication systems, NBSIR 86-3058 (October 1986).

The calibration and measurement support requirements of millimeter-wave satellite systems such as MILSTAR have been investigated. Needs for measurements on satellite systems are reviewed. An overview of the various means available for calibrating antenna gain, one of the key measurements that needs to be accurately accomplished, is presented. Essentially three new measurement problems arise because of operating in the upper SHF and EHF frequency ranges. First, without adequate methods to measure the atmospheric loss, the accuracy of effective isotropic radiated power (EIRP) measurements in the 20 to $45 \mathrm{GHz}$ range can be no better than 0.5 $\mathrm{dB}$ to $3 \mathrm{~dB}$ (depending on frequency and antenna elevation angle), which is inadequate for MILSTAR requirements. second, standards and measurement support services are not presently available from the National Bureau of Standards and are needed to support millimeter-wave antenna gain and thermal noise measurements. Third, if the sun and/or moon are to be used for measuring the earth terminal $G / T$, earth terminal antenna gain, or satellite EIRP in the millimeter region, they need to be appropriately characterized at those frequencies.

[Contact: Ramon C. Baird, (303) 497-3301]

Hill, D.A., Far-Field Transient Response of an Antenna from Near-Field Data, NBSIR 86-3063 (December 1986).

A theoretical basis for calculating the transient far-field response of an antenna from planar near-field data in either the time domain or the frequency domain has been developed. A double integral must be evaluated if we begin with time-domain data, but a triple integral must be evaluated if we begin with frequency-domain data. However, the frequency-domain integrals are in a form that is suitable for three-dimensional fast Fourier transform. Two idealized examples are studied, and identical results are obtained starting with frequency-domain or time-domain data. The main practical difficulty in determining the transient response is the large number of near-field samples that are required. If data are taken at only a few near-field points, then the singularity expansion method presents a possible method of determining the complex resonances of the antenna under test.

[Contact: David A. Hill, (303) 497-3472]

Hill, D.A., Out-of-Band Response of Reflector Antennas, IEEE Transactions on Electromagnetic Compatibility, Vol. EMC-28, No. 2, pp. 80-89 (May 1986). [This paper includes Sections 1 through 3 and Appendix A of NBSIR 85-3021, April 1985.]

The response of reflector antennas to 
Antenna Metrology (cont'd.)

out-ot-band frequencies has been analyzed using physical optics. A simple approximate expression has been obtained for the effective aperture, and this expression yields both the receiving pattern and the frequency dependence of the on-axis gain. The theory has been compared with published out-of-band measurements, and the pattern agreement is good, but the measured gain falls below the theory. This discrepancy is caused by mismatch loss in the coax-towaveguide adapter.

[Contact: David A. Hill, (303) 497-3472]

Muth, L.A., Displacement Errors in Antenna Near-Field Measurements and Their Effect on the Par Field, NBS Technical Note 1306 (October 1986).

The effects of probe displacement errors in the near-field measurement procedure on the far-field spectrum are studied. Expressions are derived for the displacement error functions that maximize the fractional error in the spectrum both for the on-axis and off-axis directions. Planar $x-y$ and $z-d i s p l a c e m e n t$ errors are studied first, and the results generalized to position errors in cylindrical and spherical scanning. Near-field models are used to obtain order-of-magnitude estimates for the fractional error as a function of relevant scale lengths of the near field, defined as the lengths over which significant variations occur.

[Contact: Lorant A. Muth, (303)

497-3603]

Noise Metrology

Recently Published

Baird, R.C., Daywitt, W.C., Newell, A.C., Perera, S., Repjar, A.G., Wait, D.F., and Estin, A.J., Calibration Requirements for EHF Satellite Comunication Systems, NBSIR 86-3058 (October 1986).

The calibration and measurement support requirements of millimeter-wave satellite systems such as MILSTAR have been investigated. Needs for measurements on satellite systems are reviewed. An overview of the various means available for calibrating antenna gain, one of the key measurements that needs to be accurately accomplished, is presented. Essentially three new measurement problems arise because of operating in the upper SHF and EHF frequency ranges. First, without adequate methods to measure the atmospheric loss, the accuracy of effective isotropic radiated power (EIRP) measurements in, the 20 to $45 \mathrm{GHz}$ range can be no better than 0.5 $\mathrm{dB}$ to $3 \mathrm{~dB}$ (depending on frequency and antenna elevation angle), which is inadequate for MILSTAR requirements. Second, standards and measurement support services are not presently available from the National Bureau of Standards and are needed to support millimeter-wave antenna gain and thermal noise measurements. Third, if the sun and/or moon are to be used for measuring the earth terminal $G / T$, earth terminal antenna gain, or satellite EIRP in the millimeter region, they need to be appropriately characterized at those frequencies.

[Contact: Ramon C. Baird, (303)

497-3301]

Microwave and Millimeter-Wave Metrology

Recently Published

Adair, R.T., Reeve, G.R., and Gatterer, L.E., Millimeter-Wave Standards: An Emerging Need, IEEE Transactions on Instrumentation and Measurement, Vol. IM-35, No. 4, pp. 376-382 (December 1986).

Several technology surveys concerning millimeter-wave (MMW) measurement needs and capabilities have been conducted by the National Bureau of Standards (NBS), Boulder Laboratories, and others. The results of some of these studies are summarized. Current MMW standards and calibration capabilities at NBS are reviewed. The lack of national stan- 
Microwave \& Millimeter-Wave (cont'd.)

dards in certain frequency bands may lead to problems with specification, acceptance testing, and calibration of some components and systems.

[Contact: Robert T. Adair, (303)

497-3461]

Ginley, R.A., and Allred, C.M., 1.25 MHz Attenuation Measurement System. IEEE Transactions on Instrumentation and Measurement, Vol. IM-35, No. 4, pp. 463-466 (December 1986).

A system has been developed to make highly accurate measurements of nominally $6-d B$ increments of attenuation at $1.25 \mathrm{MHz}$. Initial experiments indicate a typical systematic error of $5 \mu \mathrm{B}(1 \mu \mathrm{B}$ $=0.00001 \mathrm{~dB}$ ) with a resolution of $1 \mu \mathrm{B}$. A special linearity measurement system (LMS) using NBS-constructed, linear tuned hybrids and power detectors has been used to determine the nonlinearity of a tuned 1.25-MHz power detector. This detector utilizes a single thermistor bead design with thermal isolation to obtain nearly linear tracking of a $4: 1$ change in input power. The nonlinear correction for this change, determined by the LMS, is on the order of $13 \mu \mathrm{B}$ for the detector presently in use. This calibrated detector and another of similar design are used in the attenuation measurement system to make power ratio measurements to determine the change in attenuation of the device under test. It is anticipated that changes of approximately $6 \mathrm{~dB}$ can be measured with initial insertion loss of up to $100 \mathrm{~dB}$ with an accuracy of $0.001 \mathrm{~dB}$. A special design consideration will be required for units used for calibration in order to keep mismatch errors from significantly degrading the accuracies estimated above.

[Contact: Ronald A. Ginley, (303)

497-3634]

Sequeira, H.B., and Yates, B.C., Approach for Evaluating Bffects of wall Losses on Quarter-Wave Short-Circuit
Impedance standards, IEEE Transactions on Microwave Theory and Techniques, Vol. MTT-33, No. 11, pp. 11061109 (November 1985)

The conservation of energy principle and first-order perturbation theory have been applied to obtain formulas for the physical lengths and reflection coefficient magnitudes of quarter-wave coaxial and rectangular waveguide shortcircuit impedance standards. The expressions for the physical lengths ensure zero phase angle at the mating interface when wall losses are present.

The method can be extended to include small dielectric and magnetic losses, and requires only knowledge of the lossfree solutions. It can also be applied to other waveguiding structures which support uncoupled modes.

[Contact: Billie C. Yates, (303)

497-3568 ]

\section{Optical Fiber Metrology}

Released for Publication

Day, G.W., and Franzen, D.L., Conference Report: Symposium on Optical Fiber Measurements, to be published in the NBS Journal of Research.

This report is a brief summary of the 4 th Symposium on Optical Fiber Measurements, held september 9-10, 1986 at the NBS Boulder Laboratories.

[Contact: Gordon W. Day, (303)

497-5204]

Electro-Optic Metrology

Released for Publication

Franzen, D.L., Yamabayashi, Y., and Kanada, T., Optical Sampling with Gain-Switched Pulse Compressed Distributed-Feedback Laser Diodes.

Chirped pulses from gain-switched, distributed-feedback laser diodes at a wavelength of $1.3 \mu \mathrm{m}$ are compressed to 8.7 ps full width at half maximum by the 
Electro-optic Metrology (cont'd.)

\section{Released for Publication}

linear dispersion properties of single mode tiber. These pulses are used to optically sample waveforms from other laser diodes. The all-fiber sampling system uses a coupler to combine beams, thus eliminating critical alignment. [Contact: Douglas L. Franzen, (303) 497-3346 or -5342]

\section{Recently Published}

Day, G.W., Hale, P.D., Deeter, M., Milner, T.E., Conrad, D., and Etzel, S.M., High Precision Electro-Optic and Magneto-optic sensors for Power System Applications: Technical Feasibility, NBS Technical Note 1307 (March 1987).

The principles of electro-optic and magneto-optic sensors suitable for use in power system applications are reviewed with particular attention to the properties of materials and components that limit the precision of such sensors. Section topics include precision and accuracy in electro-optic and magneto-optic sensors; electro-optic and magneto-optic sensor configurations suitable for current and voltage measurements; critical evaluation of electro-optic sensor technology; critical evaluation of magneto-optic sensor technology; and suggested approaches to the development of high-precision optical current and voltage sensors. Data on a number of materials are collected and presented. For high-precision electrooptic sensors, it is recommended that crystals of the polar class having point syminetry $\overline{4} 3 \mathrm{~m}$ be used. For highprecision magneto-optic sensors, a lead glass with a low stress-optic coefficient is recommended. Choices for other components are also suggested. For both types of sensors, a precision of roughly $\pm 1 \%$ over a $100^{\circ} \mathrm{C}$ temperature range should be attainable. To achieve a precision better than that, it will be necessary to use temperature compensa- tion techniques, several of which are proposed and discussed.

[Contact: Gordon W. Day, (303)

497-5204]

Other Fast Signal Topics

Recently Published

Hill, D.A., Electromagnetic Wave propagation in an Asymetrical Coal Seam, IEEE Transactions on Antennas and Propagation, Vol. AP-34, No. 2, pp. 244-247 (February 1986).

Electromagnetic wave propagation in a coal seam is analyzed for the case where the surrounding floor and roof rocks have differing electrical properties. Numerical results are presented for the attenuation rate and field distribution of the dominant mode. Even when the roof and floor conductivities are different, the vertical electric field and the horizontal magnetic field are the dominant components, and they are nearly constant within the coal seam. The results have application to mine communication and remote sensing of coal seams.

[Contact: David A. Hill, (303) 497-3472]

Hill, D.A., and Wait, J.R., Anomalous Vertical Magnetic Field for Electronagnetic Induction in a Iaterally Varying Thin Conductive Sheet, Radio Science, Vol. 21, No. 4, pp. 617-621 (JulyAugust 1986).

We employ a simple model to show how the natural electromagnetic field on the surface of the earth, which has a strong horizontal magnetic field component, can be converted to a significant vertical magnetic field at the surface. Such a conversion mechanism will be caused by lateral variations of the subsurface conductivity structure. Our idealized model is a thin conducting sheet with a periodic variation of the conductivitythickness product in one horizontal direction only.

[Contact: David A. Hill, (303)

497-3472] 
Other Fast Signal Topics (cont'd.)

Perrey, A.G., Bell, B.A., and Treado, M.J., Evaluation of Electronic Monitoring Devices, NBSIR 86-3501 (December 1986).

Electronic Monitoring Devices (EMDs) are used to monitor the presence of individuals within a given area who are responsible to the criminal justice system but not confined to institutions. Several EMDs were tested to measure operational characteristics such as operating frequency, approximate range of operation, component capability, and tamper resistance. Tests were conducted in an open field, wooden residence, high rise metalbuilding, and in a laboratory environment.

[Contact: Arnold G. Perrey, (301)

975-2782]

\section{ELECTRICAL SYSTEMS}

Power Systems Metrology

Released for Publication

Laug, O.B., A Precision Power Amplifier for Power/Energy Calibration Applications, to be published in the Proceedings of the IMTC/87 Conference Record (IEEE Instrumentation/Measurement Technology, Conference), Boston, Massachusetts, April 27-29, 1987.

A precision power amplifier for use in power/energy calibration applications is described. The amplifier was primarily designed to boost the output amplitude of a dual-channel digital generator to provide the nominal 120 or 240 rms voltage component of a "phantom" calibration power source. The amplifier has a fixed gain of 40 and can provide a maximum output voltage swing of $970 \mathrm{~V}$ peak-topeak or $340 \mathrm{~V}$ rms at $100 \mathrm{~mA}$ rms. The banawidth is from dc to $150 \mathrm{kHz}$, and at $60 \mathrm{~Hz}$ the observed no-load, short-term amplitude and phase instabilities are \pm 5 ppm and \pm 5 microradians, respectively. The amplifier design uses high-voltage $\mathrm{N}$-channel MOSFETs in the output driver stage, together with a unique circuit topology of opto-isolators between the low-level input stage and the high-level output stage.

[Contact: Owen B. Laug, (301)

975-2412]

\section{Superconductors}

Released for Publication

Fickett, F.R., and Capobianco, T.E., Conductors for Advanced Bnergy Systems.

In this report we present the results of extensive mechanical-properties tests on a large number of oxygen-free copper samples representing a range of producers and wire tempers. Tests at both room temperature and liquid-helium temperature $(4 \mathrm{~K})$ are reported. A specialized apparatus developed for the low-temperature tests is described. Results of the many tests are presented in graphical and tabular form. The most interesting of the results is that it appears possible to predict the strength of oxygen-free copper wires at low temperatures by the measurement of the residual resistance ratio (RRR), the ratio of the room temperature resistance to that measured at $4 \mathrm{~K}$. This result is of great importance in applications, since many laboratories are able to measure RRR, but few can do low- temperature mechanical properties tests. [Contact: Frederick R. Fickett, (303) 497-3785]

Goodrich, L.F., Bray, S.L., Dube, W.P., Pittman, E.S., and Clark, A.F., Development of Standards for superconductors, Interim Report, January December 1985, to be published as NBSIR 87-3066.

A cooperative program with the Department of Energy, the National Bureau of Standards, and private industry is in progress to develop standard measurement practices for use in large-scale applications of superconductivity. The goal is the adoption of voluntary standards 


\section{Superconductors (cont'd.)}

for the critical parameters and other characterizations of practical superconductors. Progress for the period January through December 1985 is reported. The major effort was the measurement of large-conductor critical currents. other work reported here includes stability and a discussion of possible future standard Reference Materials. [Contact: Loren F. Goodrich, (303) 497-3143]

Moreland, J., Ekin, J.W., Goodrich, L.F., Capobianco, T.E., Clark, A.F., Kwo, J., and Hong, M., Break-Junction Tunneling Measurements of the High-TC Superconductor $\mathrm{Y}_{1} \mathrm{Ba}_{2} \mathrm{Cu}_{3} \mathrm{O} 9-\delta$.

Current-voltage tunneling characteristics in a high-critical-temperature superconducting material containing predominately $\quad \mathrm{Y}_{1} \mathrm{Ba}_{2} \mathrm{Cu}_{3} \mathrm{O}_{9}-\delta$ have been measured using the break-junction technique. Sharp gap structure was observed, with the largest superconductive energy gap measured to be $\Delta=19.5 \mathrm{meV} \pm$ 1 mev, assuming a superconductor-insulator-superconductor junction. Using the observed critical temperature of $93 \mathrm{~K}$ (mid-point of the resistive transition), this energy gap corresponds to $2 \Delta / \mathrm{k}_{\mathrm{BT}}=4.8$ at $\mathrm{T}=4 \mathrm{~K}$. [Contact: John Moreland, (303) 497-3641]

Moreland, J., Clark, A.F., Goodrich, L.F., Ku, H.C., and Shelton, R.N., Tunneling Spectroscopy of a La-Sr-Cu-O Break Junction: Evidence for strongCoupling Superconductivity.

Detailed structure in the quasiparticle tunneling has been observed in lanthanum-strontium-copper-oxide superconductive tunneling junctions using the break-junction technique. Variability in the energy gap and associated structure in the current-voltage curves is observed indicating significant inhomogeneity in the superconducting properties. Large energy gaps $(7.0$ to 9.0 $\mathrm{meV}$ ) and deep structure in the conduc- tance derivatives are evidence for a strong coupling mechanism.

[Contact: John Moreland, (303) 497-3641]

Moreland, J., Clark, A.F., Ku, H.C., and Shelton, R.N., Electron Tunneling Measurement of the Energy Gap in a La-Sr-Cu-O Superconductor.

The break-junction technique has been used to determine the energy gap of lanthanum-strontium-copper-oxide, one of the new high-critical-temperature superconductors. In this technique, a small piece of bulk material is electromechanically fractured under liquid helium and the freshly fractured surfaces adjusted to form a tunneling barrier with the helium as the insulator. Extraordinarily precise mechanical adjustment permits the study of electron tunneling phenomena between pieces of a bulk superconductor.

[Contact: John Moreland, (303) 497-3641]

Recently Published

Benson, R.G., Goldfarb, R.B., and Pittmann, E.S., Quench Circuit for Electronic Instruments Used with Superconducting Magnets, Cryogenics, Vol. 26 (Butterworth \& Co. Ltd., August/September 1986), pp. 482-483.

A multifunction circuit is described that protects instruments connected or coupled to a superconducting magnet in the event of a quench.

[Contact: Ronald B. Goldfarb, (303) $497-3650]$

Goldfarb, R.B, and Ekin, J.W., Hysteresis Losses in Fine-Filament InternalTin Superconductors, cryogenics, Vol. 26 (Butterworth \& Co. Ltd., August/September 1986), pp. 478-481.

Hysteresis losses were measured on a series of fine-filament $\mathrm{Nb}_{3} \mathrm{Sn}$ superconductors made by the internal-tin process. Hysteresis was measured as a function of filament diameter and inter- 
Superconductors (cont'd.)

filament separation using a vibratingsample magnetometer in transverse magnetic field. Losses were greater than expected compared to predictions of the critical-state model that expresses loss as a function of filament diameter. Micrographs of the reacted wire cross sections show some interfilament bridging for all wires. This bridging gives rise to effective filament diameters that are greater than actual diameters. The critical interfilament separation, above which the losses would be expected to follow the critical-state model, was determined.

[Contact: Ronald B. Goldfarb, (303)

497-3650]

Goldfarb, R.B., Internal Fields in Magnetic Materials and Superconductors, Cryogenics, Vol. 26 (Butterworth \& Co. Ltd., August/September 1986), pp. 621-622.

This paper reviews some of the concepts needed for the correct analysis of magnetization data, both for magnetic materials and superconductors. Demagnetization factors, initial suceptibilities, and hysteresis losses are discussed. [Contact: Ronald B. Goldfarb, (303) 497-3650]

Magnetic Materials and Measurements

Recently Published

Capobianco, T.E., Moulder, J.C., and Fickett, F.R., Flaw Detection with a Magnetic Field Gradioneter, Proceedings of the Fifteenth Symposium on Nondestructive Evaluation, San Antonio, Texas, April 23-25, 1985, pp. 15-20.

When eddy currents are induced in a conductor, tlaws deflect the eddy currents and perturb the associated electric and magnetic fields. In conventional eddy current testing, the perturbed fields associated with a flaw are detected as a change in the impedance of the test coil used to induce the eddy currents. More direct methods for detecting and characterizing flaw-perturbed fields, both electric and magnetic, have also been developed. We describe a method for determining the normal component of the magnetic field gradient caused by a flaw. A novel feature of the measurement system is the use of a Superconducting Quantum Interface Device (SQUID). The SQUID provides more sensitivity than conventional detection methods, and the possibility of calibration based on a fundamental physical quantity: the flux quantum. We report the results of a series of measurements on a fatigue crack and several manufactured defects in aluminum alloy specimens using this system. The effect of edge proximity compared to flaw signal and a figure of merit are also discussed.

[Contact: Thomas E. Capobianco, (303)

497-3141]

Goldfarb, R.B., Internal Fields in Magnetic Materials and Superconductors, Cryogenics, Vol. 26 (Butterworth \& Co. Ltd., August/September 1986), pp. 621-622.

This paper reviews some of the concepts needed for the correct analysis of magnetization data, both for magnetic materials and superconductors. Demagnetization factors, initial suceptibilities, and hysteresis losses are discussed. [Contact: Ronald B. Goldfarb, (303) 497-3650]

\section{ELECIROMAGNETIC INTERFERENCE}

Radiated Electromagnetic Interference

Released for Publication

Ma, M.T., and Bensema, W.D., Automated TEM Cell for Measuring Unintentional EM Emissions.

This paper summarizes the basic electrical properties of a transverse electromagnetic (TEM) cell, and the underlining theoretical background, based on which a TEM cell is used to measure accurately 
Radiated EMI (cont'd.)

the emission of an unknown, unintentional leakage source. The theory and measurements have been verified by the results of a simulated example and two experiments using a spherical dipole radiator and a small loop antenna. Recent development of an automated measurement system is also included.

[Contact: Mark T. Ma, (303) 497-3800]

Recently Published

Adams, J.W., and Vanzura, E., Shielding Effectiveness Measurements of Plastics, EMC Technology, pp. 39-42 (September-October 1986).

Measurement of shielding effectiveness of plastic materials presents problems because of the insulating nature of many plastics. A method of making the measurements using a flanged coaxial holder overcomes these limitations.

[Contact: John W. Adams, (303)

497-3328]

Bensema, W.D., Koepke, G.H., and Medley, H.W., Handbook for NBS Multisensor Automated EM Field Measurement System, NBSIR 86-3056 (October 1986).

A system is described that monitors and collects electromagnetic (EM) field strength information at five (optionally 10) locations simultaneously. The system has two modes of operation: (1) for sampling EM fields that are stationary for times of the order of $200 \mathrm{~ms}$, and (2) for sampling changing EM fields with a system resolution of $10 \mu \mathrm{s}$. Sensing elements for Mode 1 consist of three electrically short orthogonal dipoles mounted together, single dipole elements, or small loop antennas. Each element feeds a separate data input channel for a total of 15 (optionally 30) channels. Radiofrequency energy is converted to dc by a diode detector at each dipole. Mode 2 sensors are diode detectors driven by broadband antennas. Real-time system data processing includes calculation of field strength based on probe calibrations and processing of resultant data to satisfy measurement goals.

[Contact: William D. Bensema, (303) 497-3465]

Cruz, J.E., and Larsen, E.B., Assessment of Errors for Some Typical MIISID-461/462 Types of Measurenents, NBS Technical Note 1300 (October 1986).

This report deals with the instrumentation and equations for several systems used by the U.S. Army for electromagnetic compatibility (EMC) testing and calibrations. Most testing for MII-STD$461 / 462$ is performed in a shielded enclosure (screenroom) rather than an open field site, which leads to uncertainty in the measurement of emissions from electronic equipment, or the susceptiblity of equipment to radiation. Assessment of error bounds by the National Bureau of Standards is covered in this report, and suggestions are given for improving the measurements.

Four areas of concern were studied as follows: (a) EM fields generated in a parallel-plate transmission line (stripline), (b) EM fields beneath a singlewire transmission line in a screenroom (longwire line), (c) determination of antenna factors for EMI antennas located in a screenroom, and (d) calibration of EMI receivers to measure broadband impulsive signals. Most EMC antennas at NBS are calibrated at an open field site or in an anechoic chamber. This report presents antenna factors determined in a typical screenroom using the two-antenna method, and comparison with those determined at an open field site. The video pulse technique prescribed in MIL-STD462 for calibrating EMI receivers was also evaluated. Four different methods were tested for comparison with the MIL-STD approach. They are defined and discussed in this report.

[Contact: Jose E. Cruz, (303) 497-3763]

Jesch, R.L., A Survey of Triaxial and 
Radiated EMI (cont'd.)

Mode-Stirred Techniques for Measuring
the Shielding Effectiveness of Connectors and Cables, NBSIR 86-3060 (October 1986).

This report is the result of an extensive literature search conducted in the field of connectors and cables, with reference to radio-frequency leakage characteristics and capabilities for measuring shielding effectiveness of connectors and cables. The report reviews two measurement techniques for determining shielding effectiveness: the triaxial test technique that has been used for over 20 years and the mode-stirred test technique that recently has started to gain in popularity. From this survey, certain inferences are drawn about these techniques in terms of device configuration, frequency range, and ease of measurement and are presented in chart form for comparative purposes.

[Contact: Ramon L. Jesch, (303) 497-3496]

Kanda, M., Time-Domain Sensors and Radiators, Time-Domain Measurements in Electromagnetics, E.K. Miller, ed., Chapter 5 (Van Nostrand Reinhold Co., New York, NY, 1986), pp. 122-174.

The purpose of this chapter is to discuss various sensors and radiators commonly used for time-domain antenna measurements. The sensors and radiators discussed here are passive analog devices that convert the electromagnetic quantity of interest to a voltage or current at their terminal ports. Moreover, they are primary standards in the sense that their transfer functions can be calculated from their geometries and are flat (frequency-independent) across a wide frequency range. One of the major requirements of these sensors and radiators is that the electromagnetic far field, for transmission or reception, be a replica or high-fidelity derivative of the original pulse.

Because of their usefulness in electric- field strength measurements, linear antennas nonuniformly and continuously loaded with resistance, or both resistance and capacitance, are discussed. Also, a conical antenna and an asymptotic conical antenna are examined from the standpoint of improved antenna characteristics. Various types of transverse electromagnetic (TEM) horns are considered for improved directivity, e.g., a conducting TEM horn and a resistively loaded TEM horn. For magneticfield strength measurements, a loop antenna with uniform resistive loading is discussed.

Section 5.1 discusses one of the important properties governing the transmitting and receiving transfer functions of an antenna. The frequency-domain and time-domain characteristics of the various electric- and magnetic-field sensors mentioned above are then covered in Secs. 5.2 and 5.3, respectively. [Contact: Motohisa Kanda, (303) 497-5320]

Kanda, M., and Wyss, J.C., Evaluation of Off Axis Measurements Performed in an Anechoic Chamber, NBS Technical No te 1305 (October 1986).

The performance of a rectangular radiofrequency anechoic chamber is measured when the device under test is not on the center line of the launch antenna. An electrically small field probe is repeatedly scanned longitudinally away from the launch antenna and into the chamber. With each scan, various parameters are changed, including: 1) horizontal and vertical position of the probe with respect to the center line of the launch antenna; 2) frequency; and 3 ) type of launch antenna. With the probe located $1 \mathrm{~m}$ off the center line and scanning between 2 to 6 meters from the launch horn, the uncertainty due to being off the center line ranges from \pm 1 $\mathrm{dB}$ at $250 \mathrm{MHz}$ to $\pm 5.0 \mathrm{~dB}$ at $800 \mathrm{MHz}$ and above. If the probe is within $\pm 50 \mathrm{~cm}$ of center line, the uncertainty is no more than $\pm 1.5 \mathrm{~dB}$ at $800 \mathrm{MHz}$; and for $\pm 25 \mathrm{~cm}$ of center line, the uncertainty is fur- 
Radiated EMI (cont'd.)

ther reduced to $\pm 0.5 \mathrm{~dB}$ at $800 \mathrm{MHz}$.

[Contact: Motohisa Kanda, (303)

497-5320]

Ma, M.T., and Kanda, M., Electromagnetic Compatibility and Interference Metrology, NBS Technical Note 1099 (July 1986).

The material included in this report is intended for a short course on electromagnetic compatibility/interference (EMC/EMI) metrology to be offered jointly by the staff of the Fields Characterization Group and the Interference Characterization Group of the Electromagnetic Fields Division. The purpose of this short course is to present a review of some of the radiated EMC/EMI measurement methods, to which the National Bureau of Standards (NBS) at Boulder, Colorado, has made significant contributions during the past two decades. The technical foundation for these methods, and interpretations of the measured results are emphasized, as well as strengths and limitations. The entire course is presented in nine chapters with the introductory part given as Chapter 1. The particular measurement topics to be covered are: i) open sites (Chapters 2 and 6), ii) transverse electromagnetic cells (Chapter 3), iii) techniques for measuring the electromagnetic shielding of materials (Chapter 4), iv) anechoic chambers (Chapter 5), and v) reverberating chambers (Chapter 8). In addition, since a small probe antenna plays an important role in some of the EMC/EMI measurements covered herein, a separate chapter on various probe systems developed at NBS is given in Chapter 7. Selected contemporary EMI topics such as the characterization and measurement of a complex EM environment, interferences in the form of out-of-band receptions to an antenna, and some conducted EMI problems are also briefly discussed (Chapter 9).
[Contact:
Mark T. Ma,
(303) 497-3800]

Randa, J., and Kanda, M., A Lattice
Approach to Volumes Irradiated by Unknown Sources, NBS Technical Note 1303 (October 1986).

We suggest an approach to the characterization of electromagnetic environments irradiated by unknown sources. The approach is based on the numerical solution of Maxwell's equations subject to the constraints imposed by the measured values of the field at a small number of measurement points and by boundary conditions. A thorough examination is presented of two methods for the numerical solution. The examples attempted demonstrate the approach, but reveal that neither technique is fully successful. Possible future directions are suggested.

[A paper based on the contents of this Technical Note is scheduled for presentation at the Seventh Symposium and Technical Exhibition on EMC (Zurich, Switzerland, March 1987) under the title "A Lattice Approach to Environments Irradiated by Unknown Sources" and will appear in the proceedings of that symposium. A second paper based on this material has been submitted to the IEEE Transactions on Electromagnetic Compatibility with the title "A New Approach to Volumes Irradiated by Unknown Sources.]

[Contact: James P. Randa, (303)

497-3150]

Wilson, P.F., and Ma, M.T., Electromagnetic Shielding Effectiveness: Measurement Techniques and Interpretations, 1986 IEEE Regional Conference \& Exhibition on Electromagnetic Compatibility, Anaheim, California, February 6, 1986, pp. 1-14.

A material's shielding capability is generally measured in terms of insertion loss: the field reduction between a transmitter and a receiver achieved by introducing the shield material. Ambiguities often arise when one attempts to interpret specific measurement results. Insertion loss data depend not only on the shield material tested, but also on 
Radiated EMI (cont'd.)

the measurement procedure and other parameters such as the antenna types (both transmitting and receiving) used and their positioning, the incident waveform and its wave impedance, transient effects, and the contact resistance between the test material and its mount, if any.

[Contact: Perry F. Wilson, (303)

497-3842]

Wilson, P.F., and Ma, M.T., Methods for Measuring the Near-Field and FarField Shielding Effectiveness of Materials, Proceedings of the EMC Expo ' 86 Conference, Washington, D.C., June 16-19, 1986, pp. T281-T286.

Techniques for measuring the shielding effectiveness of materials are investigated. Specific approaches considered are coaxial transmission line holders and the use of a time-domain signal for simulating plane wave shielding performance, and the dual transverse electromagnetic (TEM) cell and an apertured TEM cell in a reverberation chamber for the simulation of near-field shielding capability. The advantages and limitations of each technique are summarized.

[Contact: Perry F. Wilson, (303)

497-3842]

\section{ADDITIONAL INPORMATION}

\section{Lists of Publications}

Gibson, K.A., Page, J.M., and Miller, C.K.S., A Bibliography of the NBS Electromagnetic Fields Division Publications, NBSIR 85-3040 (February 1986).

This bibliography lists publications of the National Bureau of Standards' Electromagnetic Fields Division for the period from January 1984 through September 1985, with selected earlier publications from the Division's predecessor organizations.

[Contact: Kathryn A. Gibson, (303)

497-3132]
Kline, K.E., and DeWeese, M.E., Metrology for Electromagnetic Technology: A Bibliography of NBS Publications, NBSIR 86-3048 (June 1986).

This bibliography lists the publications of the personnel of the Electromagnetic Technology Division of NBS in the period from January 1970 through December 1985. A few earlier references that are directly related to the present work of the Division are included.

[Contact: Kathryn E. Kline, (303)

497-3678]

Palla, J.C., and Meiselman, B., Electrical and Blectronic Metrology: A Bibliography of NBS Electrosystems Division Publications, NBS Iist of Publications 94 (January 1987).

This bibliography covers publications of the Electrosystems Division, Center for Electronics and Electrical Engineering, NBS, and of its predecessor sections for the period January 1963 to January 1987. A brief description of the Division's technical program is given in the introduction.

[Contact: Jenny C. Palla, (301)

975-2220]

Walters, E.J., Semiconductor Measurement Technology: A Bibliography of NBS Publications for the Years 1962-1986, NBSIR 87-3522 (February 1987).

This bibliography contains reports of work performed at the National Bureau of Standards in the field of Semiconductor Measurement Technology in the period from 1962 through December 1986. An index by topic area and a list of authors are provided.

[Contact: E. Jane Walters, (301)

975-2050]

\section{CEEEE CALENDAR}

July 28-30 (Vail, CO)

Short Course on Optical Fiber Measurements. This course is sponsored by the National Bureau of Standards and the 
1987 CEEE Calendar (cont'd.)

University of Colorado with the cooperation of members of industry who serve as faculty together with staff from the Electromagnetic Technology and Electromagnetic fields Divisions. The course is intended for scientists and engineers involved in optical fiber characterization and emphasizes concepts, techniques, and apparatus used in measuring engineering parameters of telecommunications-grade fibers.

The following major topic areas are addressed: optics for communications, emphasizing geometric optics concepts; fiber properties and parameters; indexprofile measurements; fiber bandwidth measurements in the frequency and time domains; fiber attenuation measurements; connector and splice losses; optical time-domain reflectometry concepts and applications; single-mode fibers; statistics and error analyses, measurement uncertainties; and fibers for sensors. [Contact: office of Conference Services, University of Colorado (303) 492-8630; Robert L. Gallawa (303) 497-3761; or Matt Young (303) 497-3223]

September 14-16 (Research Triangle Park, $\mathrm{NC)}$

\section{VLSI and GaAs Packaging Workshop.} This Workshop is co-sponsored by the Components, Hybrids, and Manufacturing Technology society of IEEE and NBS; attendees are expected to be knowledgeable in the field and to participate in discussions. Topic areas include: VLSI and wafer scale package design (characterization and implementation, cost and performance driven solutions); package thermal design (characteristics, results, and issues); package interconnection options (wire bonding, TAB, flip nection options (wire bonding, TAB, flip chip, or optical); GaAs IC packaging (high speed packaging considerations); package electrical issues (reduction of parasitics and improvements in electrical performances); integrating package design (from die to system, including assembly and test issues); VLSI package materials advancements; die-attach solutions for large chips; new failure mechanisms in VLSI packaging. [Contact: George G. Harman, (301) 975-2097]

September 16-18 (Gaithersburg, MD)

Workshop on the Role of Optical Sensors in Power Systems' Voltage and Current Measurements. This workshop is sponsored by NBS, the Bonneville Power Administration (BPA), the Electric Power Research Institute (EPRI), and the Empire State Electric Energy Research Corporation (ESEERC) and is intended for research and development engineers in utilities and in companies that supply equipment to the utility industry. The objective of this workshop is to identify anticipated opportunities for improved measurement techniques that should arise as power systems individually and collectively evolve to meet the needs of the 1990s. Presentations will stress the design and testing of optical systems for $60-\mathrm{Hz}$ voltage or current measurement; the interfacing of electronic or optical components with existing metering and control systems; opportunities for new measurement hardware resulting from increased automated control of power systems and of the testing of power system components; and optical techniques for the measurement of electric and magnetic fields in power systems or system components. The results of an NBS study evaluating optical techniques for power-system electrical measurements and carried out in agreement with BPA, EPRI, and ESEERC will be presented as an invited keynote. [Contact: Raymond S. Turgel, (301) 975-2420 or Robert E. Hebner, (301) 975-2403]

September 22-25 (Boulder, CO)

Noise Measurement Seminar. This fourday course is presented and hosted by the Electromagnetic Fields Division in cooperation with representatives from industry and the NBS Time and Frequency Division. It is intended for practicing noise metrologists and technical mana- 
1987 CEEE Calendar (cont'd.)

gers responsible for systems in which accurate measurements of thermal and phase noise are important. Attendees will learn the most important precautions to take in making accurate noise measurements and will receive a set of notes that are suitable for use in solving precision noise measurement problems. Course topics include reference thermal noise sources; thermal noise measuring systems and techniques; phase noise; and the problems of measuring thermal noise in passive components, amplifiers, and communication systems.

The course design combines formal lectures on theory presented by NBS staff and industry experts with demonstrations in NBS laboratories and demonstrations of commercial equipment. A special feature of the Seminar is the opportunity each day for attendees to share their experiences in solving specific problems or their insights on practical noise measurement issues through short presentations to the assembled group. Time is scheduled for group discussions of these presentations and other topics raised by the Seminar. [Contact: Sunchana Perera (303) 497-3546]

October 26-28 (Boulder, CO)

Symposium on Optical Materials for High Power Lasers (Nineteenth Boulder Damage Symposium). This Symposium is cosponsored by the National Bureau of Standards, the American Society for Testing and Materials, the Air Force office of Scientific Research, the Office of Naval Research, and the Defense Advanced Research Projects Agency and constitutes a principal forum for the exchange of information on the physics and technology of materials for highpower lasers.

Topics to be discussed include new materials, bulk damage phenomena, surface and thin-film damage, design considerations for high-power systems, and fundamental mechanisms of laser-induced damage. Proceedings of the symposium will be published (Note: The collection of Symposium proceedings contains information on optics for all aspects of high-power/high-energy lasers, including environmental degradation, durability, fabrication, material growth and deposition processes, and testing). [Contact: Susie A. Rivera (303) 497-5342]

\section{December 10-11 (Gaithersburg, MD)}

\section{Power Semiconductor Devices Workshop.} This Workshop, sponsored jointly by IEEE and NBS, is intended to bring together for interactive participation those actively working in the field of power semiconductor devices. It will be held in conjunction with the 1987 IEEE International Electron Devices Meeting in Washington, DC. Four specific topic areas have been selected, based on the response to a questionnaire sent to over 200 power device researchers worldwide. They are: power and high voltage integrated circuits, discrete devices, device modeling, and packaging. Attendees are expected to be prepared to contribute to the development of responses to specific questions that arise in the context of the particular topic areas; a final schedule identifying the topic areas should be available at the end of October. [Contact: David L. Blackburn, (301) 975-2053]

\section{CEEE Calendar}

February 10-12 (San Diego, CA)

IEEE Semiconductor Thermal and Temperature Measurement symposium. This fourth annual SEMI-THERM symposium is sponsored by the Components, Hybrids, and Manufacturing technology Society of IEEE in cooperation with NBS and constitutes an international forum for the presentation of new developments in, and applications relating to, generation and removal of heat within semiconductor devices and measurement of junction temperatures experienced in various applications and environments. Major SEMI-THERM topic areas include thermal measurements, thermal characterization, applications, and computations and 


\section{CEEE Calendar (cont'd.)}

sof tware.

The program includes keynote speakers, technical presentations, tutorial sessions, workshops, and an exhibit. In addition, the Semiconductor Equipment and Materials Institute has scheduled in conjunction with SEMI-THERM a meeting of its Thermal Measurements Task Force, to which attendees are invited. [Contact: Frank F. Oettinger, (301) 975-2054]

May 11-13 (Los Angeles, CA)

Intersociety conference on Thermal Phenomena in Fabrication and operation of Electronic components. This conference is sponsored by the Components, Hybrids, and Manufacturing Technology Society of the IEEE, in cooperation with ASME Committee $\mathrm{K}-16$ on Heat Transfer and NBS. It is intended to provide an interdisciplinary forum for exploring the progress made in understanding, analyzing, and modeling thermal transport processes and thermally induced failures in the fabrication, assembly, and use of logic, memory, and datastorage systems. Major topic areas covered are 1) processing and fabrication, including state-of-the-art semiconductor crystal growing techniques; thermal stress in wafers, chips, substrates, PC boards, and joints; and encapsulant behavior with respect to solidification, outgassing, mechanical properties, and water vapor diffusion and absorption; 2) packaging technology, including means for cooling components from cryogenic to high temperatures and reliability as affected by failure mechanisms such as dopant migration and intermetallic growth; and 3) peripheral equipment, including data storage in both magnetic and optical media and thermal issues in dot-matrix and thermal printer heads. The conference is being held in conjunction with the Electronics Components Conference (May 9-11) at the same site. [Contact: Frank F. Oettinger, (301) 975-2054]

Planned

Early summer (Vail, CO)
Combined Short Course on Optical Fiber and Laser Measurements. [Contact: Aaron A. Sanders, (303) 497-5341]

Early fall (Boulder, CO)

Fiber Optics symposium. [Contact: Aaron A. Sanders, (303) 497-5341]

Late fall (Boulder, $\mathrm{CO}$ )

Symposium on Optical Materials for High Power Lasers (20th Boulder Damage Symposium). [Contact: Aaron A. Sanders, (303) 497-5341]

\section{CEEE SPONSORS}

National Bureau of Standards

Department of Defense

Defense Nuclear Agency; Defense

Advanced Research Projects Agency;

National Security Agency;

Combined Army/Navy/Air Force

Calibration Coordination Group

U.S. Air Force

Newark Air Force Station; Rome Air Development; Space \& Missile

Organization; Hanscom Air Force Base; Wright-Patterson Air Force Base

U.S. Army

Aviation System Command; Fort

Belvoir; Fort Monmouth; Harry Diamond Laboratories; Materials \& Mechanics Research; Strategic Defense Command

U.S. Navy

Naval Surface Weapons Center; Naval

Ocean Systems Center; Naval Ordnance

Systems Command; Naval Air Test

Center; Ordnance Disposal Technology

Center; Weapons Support Center/Crane;

Office of Naval Research; Naval Air

Engineering Center

Department of Energy

Energy Systems Research; Fusion

Energy; High Energy \& Nuclear

Physics; Bonneville Power

Administration

Department of Justice

Law Enforcement Assistance

Administration

Nuclear Regulatory Agency

Department of Treasury

Bureau of Engraving and Printing

Department of Transportation

National Highway Traffic Safety

The Charles Stark Draper Laboratory

International Copper Research

Association

Sandia National Laboratories

University of California

Los Alamos Scientific Laboratory 


NBS-114A (REV. 2-8C)

U.S. DEPT. OF COMM.

BIBLIOGRAPHIC DATA

SHEET (See instructions)

1. PUBLICATION OR REPORT NO.

NBSIR $87-3589$
2. Performing Organ. Report Nod 3. Publication Date

July 1987

4. TITLE AND SUBTITLE

Center for Electronics and Electrical Engineering Technical Progress Bulletin Covering Center Programs, January to March 1987, with 1987 CEEE Events Calendar

\section{5. $\operatorname{AUTHOR}(S)$}

E. Jane Walters, compiler

6. PERFORMING ORGANIZATION (If joint or other than NBS, see instructions)

7. Contract/Grant No.

NATIONAL BUREAU OF STANDARDS

U.S. DEPARTMENT OF COMMERCE

GAITHERSBURG, MD 20899

8. Type of Report \& Period Covered

January-March 1987

9. SPONSORING ORGANIZATION NAME AND COMPLETE ADDRESS (Street, City, Stote, ZIP)

10. SUPPLEMENTARY NOTES

All technical information included in this document has been approved for publication previously.

Document describes a computer program; SF-185, FIPS Software Summary, is attached.

11. ABSTRACT (A 200-word or less factual summary of most significant information. If document includes a significant bibliography or literature survey, mention it here)

This is the eighteenth issue of a quarterly. publication providing information on the technical work of the National. Bureau of Standards Center for Electronics and Electrical Engineering. This issue of the CEEE Technical Progress Bulletin covers the first quarter of calendar year 1987. Abstracts are provided by technical area for both published papers and papers approved by NBS for publication.

12. KEY WORDS (Six to twelve entries; alphabetical order: capitalize only proper names; and separate key words by semicolons) antennas; electrical engineering; electrical power; electromagnetic interference; electronics; instrumentation; laser; magnetics; microwave; optical fibers; semiconductors; superconductors

13. AVAILABILITY

XXXnlimited

$\square$ For Official Distribution. Do Not Release to NTIS

Order From Superintendent of Documents, U.S. Government Printing Office, Washington, D.C. 20402.

XX. Order From National Technical Information Service (NTIS), Springfield, VA. 22161
14. NO. OF PRINTED PAGES

26

15. Price

$\$ 11.95$ 
OFFICLAL BUSINESS

PENALTY FOR PRIVATE USE $\$ 300$

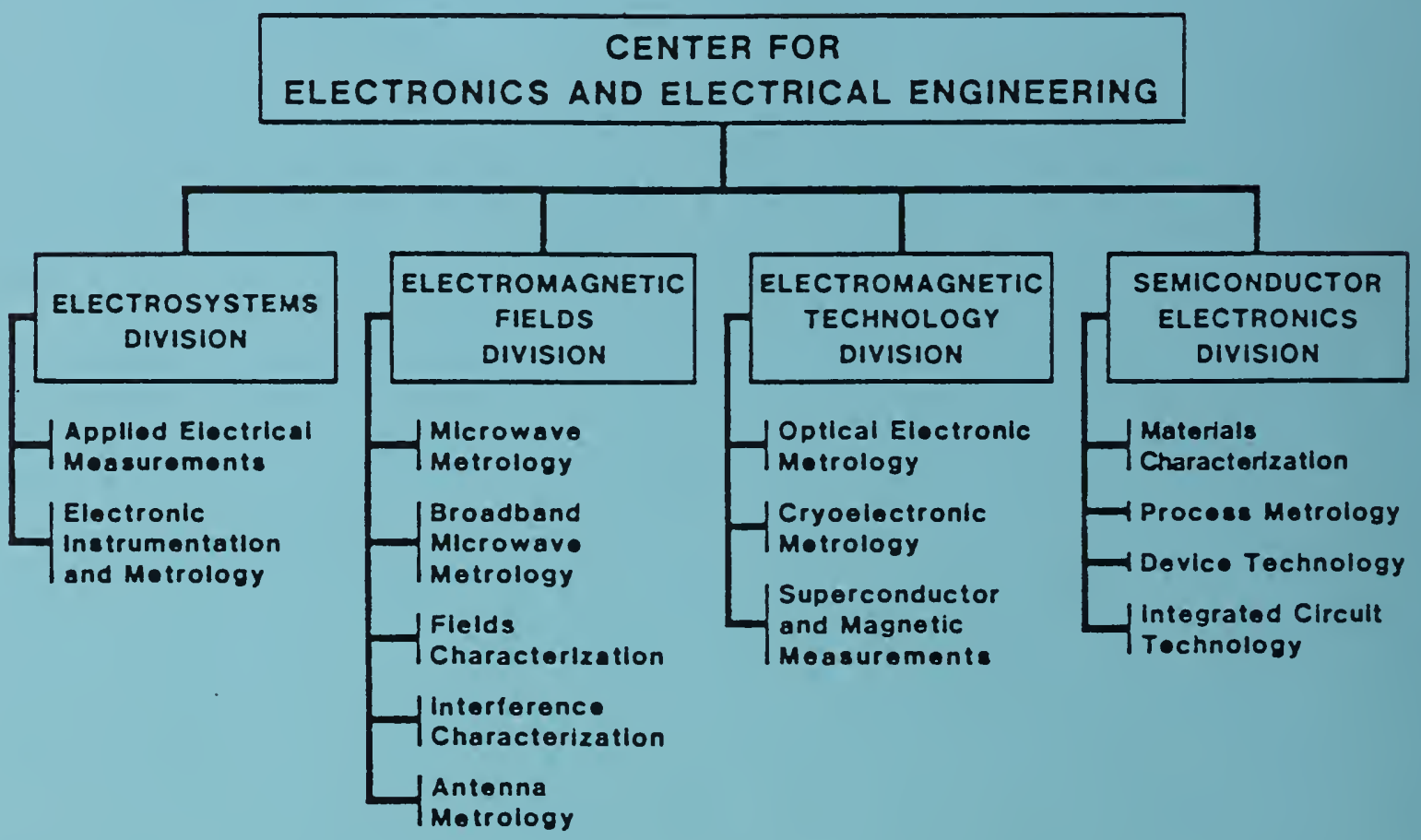

KEY CONTACTS:

Center Headquarters (720)

Electrosystems Division (722)

Electromagnetlc Flelds Division (723)

Electromagnetlc Technology Dlvislon (724)

Semlconductor Electronics Division (727)

INFORMATION:

For additional Informatlon on the Center for Electronlcs and Electrical Engineering, write or call:
Director, Mr. Judson C. French (301) 875-2220 Deputy Director, Mr. Robert I. Scace (301) 975-2220

Chlef, Dr. Oskars Petersons (301) 975-2400 Chlef, Dr. Ramon C. Balrd (303) 487-3131 Chlef, Dr. Robert A. Kamper (303) 497-3535 Chlef, Mr. Frank F. Oettinger (301) 975-2054

Center for Electronics and Electrical Englneering Natlonal Bureau of Standards Metrology Bullding, Room B-358 Gatthersburg, MD 20898

Telephone (301) 975-2220 